\title{
Editorial \\ El reto de avanzar hacia una cultura de publicación científica
}

DOI: https://doi.org/10.5377/alerta.v3i1.9275

La investigación científica está presente en nuestra cotidianidad sin siquiera darnos cuenta. La tecnología, la innovación, la globalización y todo lo que hoy en día se puede ver, es producto de un proceso previo de prueba y error; de recabar evidencias y ponerlas al servicio de los seres humanos, con el objetivo de mejorar su calidad de vida.

Las investigaciones científicas en salud son una de las más importantes y necesarias en la sociedad actual. Solo por medio de la evidencia científica, su publicación y divulgación, los tomadores de decisiones podrán adoptar medidas para mejorar la calidad de vida de sus habitantes. Por ello, convencer a un investigador a postular un manuscrito para publicación o a una institución de apostarle a este tipo de iniciativas, se vuelve un reto cada vez más urgente de superar en nuestro país.

Desde la Revista Alerta se abre un espacio de divulgación y promoción de esa cultura científica. Es por eso que hoy por hoy nos encontramos en un proceso de actualización y renovación, con el fin de cumplir los estándares internacionales e indizarla en los buscadores más importantes a nivel mundial y comenzar a posicionar a El Salvador en mejores índices bibliométricos de la investigación científica. Hasta el momento, Alerta se encuentra indizada en sitios como Latindex, REDIB, CiteFactor, Lamjol y muy pronto en LILACS. El camino no ha sido fácil, pero el avance es notorio; mantener y hacer sostenible la indexación es el reto actual.

Es precisamente por cumplir con esos requerimientos internacionales que el nuevo número de esta revista ha sufrido un cambio en su estructura y línea gráfica. Así, las secciones actuales en las que investigadores pueden publicar son: Artículo Original, Artículo de Revisión, Comunicaciones Breves, Informes de Casos y Cartas al Editor. Esto obedece a un criterio de LILACS, donde las secciones se organizan según estructura de los manuscritos y no por sus tópicos.

Para el Volumen 3, Número 1, Año 2020, Alerta presenta temáticas relacionadas con la infección tuberculosa latente en personal de salud en la América Latina, asociación entre tuberculosis y diabetes mellitus, así como tres informes de casos clínicos en ginecoobstetricia, dermatología y radiología.

El interés de los autores por publicar sus investigaciones cada vez se vuelve más recurrente y demandante. Los científicos que postulan sus manuscritos pueden confiar en que esta revista realiza un proceso de revisión por pares doble ciego, empleando un sistema de gestión en línea como el Open Journal Systems (OJS), que garantiza la transparencia del proceso editorial y se adhiere a las normas y códigos de ética 
internacionales establecidos, como el Comité Internacional de Editores de Revistas Médicas (ICMJE, por sus siglas en inglés), el Comité de Ética en Publicación (COPE, por sus siglas en inglés) y el Consejo de Organizaciones Internacionales de Ciencias Médicas (CIOMS, por sus siglas en inglés), por mencionar algunos.
El reto de una cultura de publicación científica es grande, pero la disciplina, tenacidad y compromiso de los investigadores es aún mayor. En el 2020 vamos por más, encaminados a la ciencia, innovación y excelencia en salud pública. Invitamos a toda la comunidad científica a que se sume a éste esfuerzo.

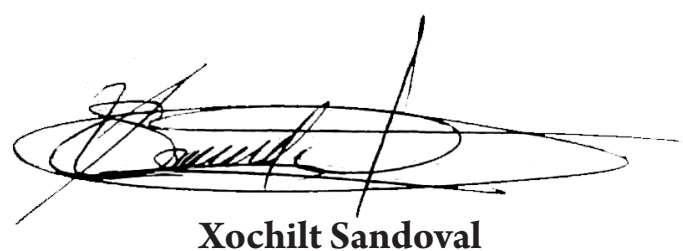

Subdirectora del Instituto Nacional de Salud 